\title{
MISSION COMMAND PRINCIPLES IN THE BATTLE OF CHIPYONG-NI
}

\author{
Daniel Patryk Michalski, DSocSci., \\ Fires Center of Excellence \\ 5690 Geronimo Road, \\ Fort Sill, \\ OK, 73503, \\ The United States of America \\ michalski.ikfs@gmail.com
}

\begin{abstract}
The article focuses on mission command principles and their impact on the on the Chipyong-ni battle. At the beginning of the paper the author presents an overview of the battle and general characteristic of the lead commander. In the following section there is a discussion of each mission command principle laid out by the U.S. Army doctrine, as well as their influence on the conducted battle. The conducted research was based on available literature.
\end{abstract}

Keywords: mission command principle, Chipyong-ni battle, leaders in battle, col. Freeman

\section{INTRODUCTION}

In military literature, the Chipyong-ni battle is described as "one of the most bitterly contested engagements of Korean War." Due to that reason, it is important for current leaders not only to know and understand what happened in this battle but also how the commanders used mission command philosophy, and how it affected the conduct of the battle. According to the Mission Command U.S. Doctrine, the mission command concept provides commanders the tools to "counter the uncertainty of operations by reducing the amount of certainty needed to act." ${ }^{2}$ That means the mission command provides the subordinate leaders and staff with the capability to act on a concept instead of relying on a detailed plan for execution. Furthermore, the doctrine mentioned above defines an approach to be adopted by the soldiers how to interact with the unknown during the Korean War; "They exploited the dynamics of human relationships to the advantage of friendly forces and to the disadvantage of an enemy." 3 Nevertheless, even if the mission command principles ware not known, the "scientific side" of war waging was evident during the battle of Chipyong-ni. The commander of the $23^{\text {rd }}$ infantry regiment used these principles, and thanks to that, led his troops to victory. This paper will analyze how the commander of the $23^{\text {rd }}$ infantry regiment used the mission command principles, and how that affected the mission. In order to achieve that research objective, the paper will present a general overview of the battle, the characteristic of the commander, and present the mission command principles used in the Chipyong-ni battle.

\footnotetext{
1 Lt. COL K.A. Landry, Leadership in Battle: The Siege at Chipyong-ni, Army article, September 2002, p. 52.

2 Department of the Army, ADP 6-0, Mission Command, Washington, DC: Government Printing Office, 12 March 2014.

3 Department of the Army, ADP 6-0, Mission Command, Washington, DC: Government Printing Office, 12 March 2014
}

\section{THE BATTLE BACKGROUND}

The battle of Chipyong-ni took place during the Korean War from February $13-15,1951$ between the $23^{\text {rd }}$ Infantry Regiment (which included U.S. and French soldiers) and various units of the Chinese army. After the United Nations (UN) withdrew from Northern Korea following the Chinese offensive at the end of 1950 , the $23^{\text {rd }}$ Infantry moved into the area of operation on February 5 after destroying the $125^{\text {th }}$ Division in the battle of the Twins Tunnels. They wanted to join the 9th Infantry near Yoju, but after the Twin Tunnels victory, the division commander gave the order to the $23^{\text {rd }}$ infantry to stay and fight. On February 16, the commander of the $23^{\text {rd }}$ Regiment received the following message from the Division, "our forces are executing a withdrawal except you. You are to remain by order of General Ridgway."4

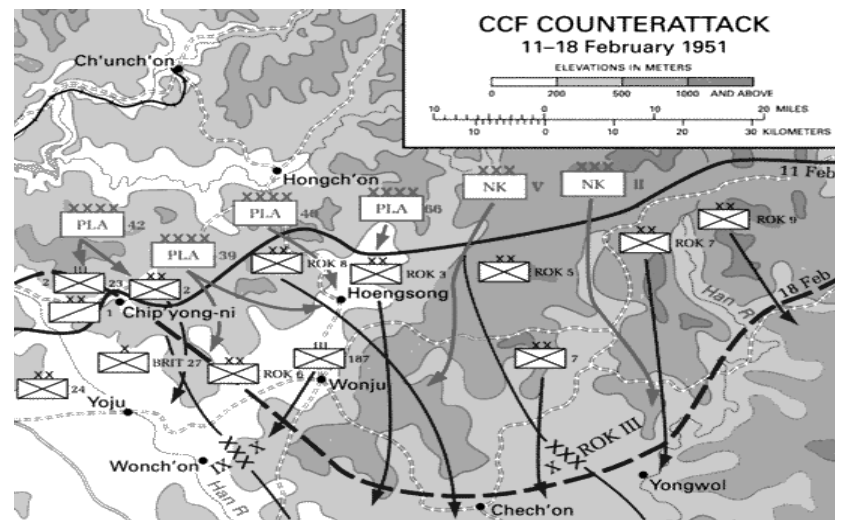

Picture 1. Background of the Chipiong-ni battle.

Source: http://www.yule-tide.com/a-blog/post-147-chipyong-nifeb-1951-the-gettysburg-of-korea

The mission of the $23^{\text {rd }}$ Regiment was to deny the enemy the use of the road and hold the area that would become the left flank of the $3^{\text {rd }}$ ROK Division when it maneuvered

4 L. Barron, Korean War, Stackpole Books, USA 2015, p. 142. 
into line before attacking to the north. The task assigned to the $23^{\text {rd }}$ Regiment was especially difficult due to the fact the division executed a withdraw during the Chinese attack leaving only the $23^{\text {rd }}$ Regiment at Chipyong-ni behind the enemy lines and exposed to a Chinese attack by surrounding forces. The area of operation was a small village Chipyon-ni located 12 miles due north of Yoju across the Han River. During the Korean War this location was very important geographically, due to the main supply routes from south to north in this spot. The commander of the $23^{\text {rd }}$ Regiment knew that the area was not only important for friendly forces but for the enemy as well. Based on knowledge of the enemy, the environment, and his orders from the Division Commander of the $23^{\text {rd }}$ Infantry Regiment, he decided to "occupy the largest ring of low hills they could man while keeping a small reserve-the largest ring they could afford in order to fully man the perimeter without any breaches." 5

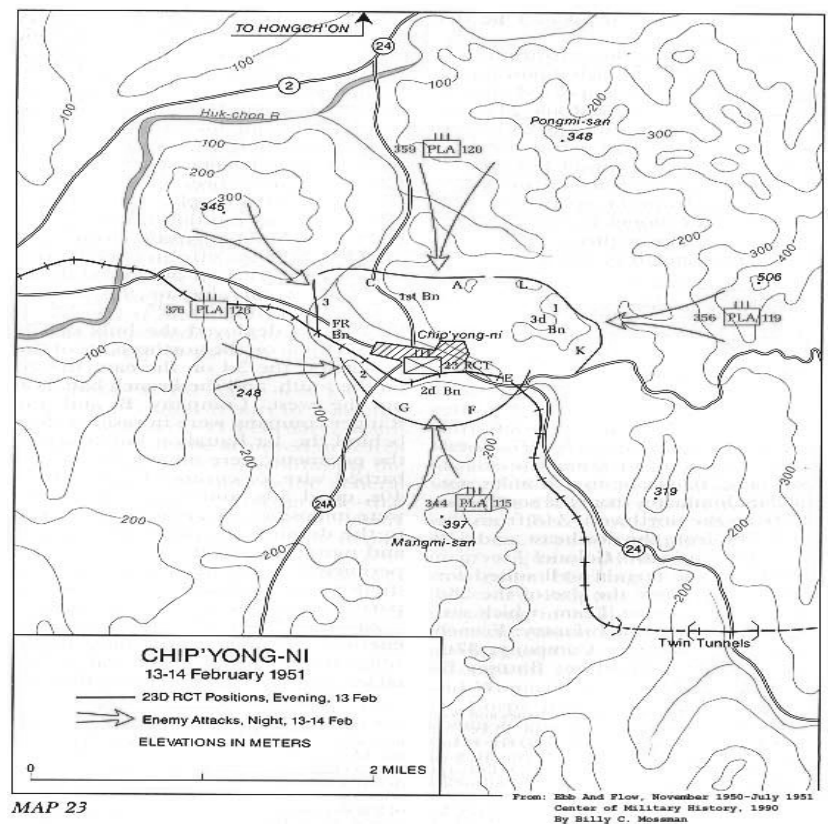

Picture 2. The Chipyong-ni Battle Map

Source: http://wolfhowling.blogspot.kr/2011/02/battles-thatchanged-history-chip-yong.html

The final perimeter was an oval measuring approximately a mile from north to south and about a mile and half from west to east.

The behavior and orders of the unit commander determine action of all subordinate soldiers. The commander has the biggest influence over their soldiers not only directly by giving them orders, but also indirectly by showing their attitude. In order to gain an understanding about the principles used during the Chipyon-ni battle, it is important to know not only the tactics used during the battle but also basic characteristics of the unit leader. The Commander of the $23^{\text {rd }}$ Regiment was Paul L. Freeman Jr. He was born on June 29, 1907. He graduated from West Point in 1929, before getting assigned to several units where

5 K.E. Hamburger, Leadership in the Crucible, USA 2003, p. 20. he got experience as a commander (for instance he deployed to China, in 1936). He developed great skills to build relationships. One of his classmates from the military academy wrote about him, "In a manner characteristic of his placid and pleasing nature, Paul entered Beast Barracks unnoticed by and unknown to many, but it was long before he was the boon companion of many and well liked by all." Freeman took command of the $23^{\text {rd }}$ Regiment in June 1950. His command philosophy was demonstrated by his actions. "He believed that he needed to go where his men would see him." "His behavior and the way he acted showed his approach to subordinate soldiers and his great commander skills which had a great impact on his future action during the Chipyong-ni battle.

\section{THE MISSION COMMAND PRINCIPLES}

\section{The Build Cohesive Teams through Mutual Trust Principle}

In fact, "building cohesive teams through mutual trust" is the first principle of mission command. Mutual trust is confidence between partners and between commanders and their subordinates. According to ADRP 6-0: "Trust is gained or lost through everyday actions more than grand or occasional gestures. It is based on personal qualities, such as professional competence, personal example, and integrity." $"$ This principle of mission command is the hardest to achieve by the commander because a great amount of time is needed to build trust and deeper relationships in the unit. COL Freeman achieved through the way he approached his soldiers. "He gives commands in person, often with a grin, a handshake, or a word of encouragement before a dangerous mission." Sometimes small things like a handshake can build an interpersonal relationship. This includes simple everyday acts of genuine human warmth and consideration motivated by a sincere concern for soldiers' welfare. It is these simple things that commander of the $23^{\text {rd }}$ Regiment did, and thanks to these unremarkable and easily overlooked daily actions he led his people to success.

It is believed that trust is not earned through heroic gestures or grand turns of phrase, but these gestures have a big influence to build up and maintain this trust, especially in a hard battle like Chipyon-ni. During the battle, Freeman showed courage when he was wounded in the leg by a shell fragment, and refused evacuation ${ }^{10}$. That act of courage showed soldiers that Freeman is concerned about his unit and his people even more than his own life. "The inspiration soldiers felt as they watched Freeman laboriously make his way around the perimeter with a walking stick the morning after he was wounded is immeasurable, because every

\footnotetext{
6 K.E. Hamburger, Leadership in the Crucible, USA 2003, p. 20.

7 K.E. Hamburger, Leadership in the Crucible, USA 2003, p. 68.

8 Department of the Army, ADP 6-0, Mission Command, Washington,

DC: Government Printing Office, 12 March 2014.

9 K.E. Hamburger, Leadership in the Crucible, USA 2003, p. 68.

10 See: S.C. Tucker (ed.), Encyclopedia of the Korean War: A political, Social, and military History, Vol. 1, California 2000.
} 
soldiers who saw him knew that freeman was worried about their welfare."

The Army's leadership doctrine rightfully states that trust enables mission command. The value of trust in the unit is specially showed in the battle of Chipyong-ni. The unit formation already shows trust between commanders and subordinates. Formation in oval require coherent trust, because everyone is responsible for the whole, as one of the soldiers recalls "We had no place to go that you could not walk to in a few minutes. The Regimental perimeter was not much bigger than the Pentagon." "11 That short distance between units provides defense needed to avoid infiltration into the weak areas or the breakthrough by even strong enemy force. All of this is a proof that Freeman built and maintained cohesive teams through mutual trust.

\section{The Create Shared Understanding Principle}

It is important that the team not only develops a shared confidence in the leaders, but also focusses on developing confidence amongst their subordinates acting in positions above their own. Once it is achieved, it will enhance the subordinates' understanding of their leaders' positions, and will better prepare the team for unpredictable changes. According the ADRP 6-0, "A critical challenge for commanders, staffs, and unified action partners is creating shared understanding of their operational environment, the operation's purpose, problems, and approaches to solving them." 12 This means that a commander has to make their people understanding the objective of the mission, but also they need to be ready to solve the problems during the mission.

In order to provide shared understanding, Freeman used collaboration and dialogue of the operational environment and concerns. He invested his time to visit his subordinate leaders and answer their questions. Moreover, the regimental leaders have a responsibility to those whom they lead to question orders they think are inappropriate. "The leader who believes he knows more about the military situation at the moment then the staff officers or commander who issued questionable orders has the responsibility to at least ask whether the current situation has been properly assessed."13 This quote shows that Freeman created a collaboration in his unit towards one goal. He established human connections and created a shared understanding by using dialogue to build trust and facilitate information sharing.

Freemans' order to take a small area and prepare the defense is an example of that mission command principle. "Freeman called his commanders together and told them that regiment was probably surrounded but that he intended to stay and fight it out." The analysis of this sentence shows that he provide purpose for the mission; "stay and fight." He also gave information

11 L. Barron, Korean War, Stackpole Books, USA 2015, p. 54.

12 Department of the Army, ADRP 6-0, Mission Command, Washington, DC: Government Printing Office, May 2012.

13 K.E. Hamburger, Leadership in the Crucible, USA 2003, p. 35. of the operational environment; "The regiment was probably surrounded." Due to the shared understanding provided by the commander of the $23^{\text {rd }}$ Regiment, he resolved potential misunderstandings and created opportunity to address problems and challenges.

\section{The Provide a Clear Commander's Intent Principle}

Clear commander's intent is directly connected with the "shared understanding" principle mentioned above. The Mission Command Army Doctrine explains clear intent as, "Commanders articulate the overall reason for the operation so forces understand why it is being conducted." 14 This principle of mission command provides not only focus to the staff but also helps subordinates act to achieve the objectives. Most importantly, commander's intent is an essential component to drive the operations process that consists of: to understand, visualize, describe, direct, lead, and assess. Based on available rescores, COL Freeman used this principle during the preparation to the battle. The study of the literature confirmed that thesis. An example used before (in the shared understanding paragraph) confirmed that Freeman used not only shared understanding but also provided a clear commander's intent. "Freeman called his commanders together and told them that regiment was probably surrounded but that he intended to stay and fight it out." ${ }^{15} \mathrm{He}$ used the overall reason for the operation so his subordinates understood why it was being conducted. He explained that "He especially wanted to avoid any gaps like those that had given the Chinese an opportunity to attack between units at the tunnels." 16 As a result, the subordinates knew the purpose of the operation and they could start preparations for the battle. Moreover, during the battle Freeman used this mission command principle. It is shown specifically during the counterattack when he explained the reason and purpose of the mission to his subordinates. "Chinese forces broke through the perimeter and forced the defenders out of their positions, a serious threat to the beleaguered regiment. Freeman ordered the Ranger Company, a platoon from F Company, and 14 men from G Company to counterattack." ${ }^{17}$ Once more, he explained what the purpose of the order, which was to provide understanding and clear intent. That leaves no doubt that the commander of $23^{\text {rd }}$ Regiment used shared understanding and clear intent in the Chipyon-ni battle.

Freeman used a clear commander's intent in his orders to staff and subordinate leaders to develop plans and orders that transformed into action. His order provided a vision of what they ultimately wanted to accomplish. What is more, he avoided misunderstandings by using a well-crafted commander's intent to convey a clear image of the operational purpose and tasks, even if the mission was complicated and hard to conduct.

14 Department of the Army, ADP 6-0, Mission Command, Washington, DC: Government Printing Office, 12 March 2014.

15 K.E. Hamburger, Leadership in the Crucible, USA 2003, p. 57.

16 K.E. Hamburger, Leadership in the Crucible, USA 2003, p. 62.

17 L. Barron, Korean War, Stackpole Books, USA 2015, p. 87. 
The Exercise Disciplined Initiative and Use Mission Orders Principle

Mission accomplishment requires disciplined initiative at every level to achieve a Commander's intent and accomplish a mission. The military understanding of this mission command principle is "Leaders and subordinates who exercise disciplined initiative create opportunity by taking action to develop the situation. Disciplined initiative is action in the absence of orders, when existing orders no longer fit the situation, or when unforeseen opportunities or threats arise. Commanders rely on subordinates to act." ${ }^{18}$ It is related with the next mission command principle "use mission orders," due to the way commanders give orders to allow an initiative on the part of their subordinates. According Mission Command army doctrine, the Mission orders are "directives that emphasize to subordinates the results to be attained, not how they are to achieve them."19 That means that the commander trusts their subordinates by giving general intent along with a minimum level of instruction that dictates how the subordinate should conduct the operation.

Both, mission orders and disciplined initiative, are dependent on the level of complexity of the mission and experience of lower level leaders. If a lot of elements have to be coordinated during the mission, commanders must give more specific orders to avoid unnecessary risk. During the Chipyong-ni battle, COL Freeman had to coordinate each regiment unit to avoid gaps between them and not give the enemy an opportunity to attack between units. Nevertheless, the literature shows that during the battle "both commanders, and many of their subordinates, had a particular facility for planning in detail, assessing and changing situation, and continually assimilating large quantities of often-conflicting data. They combined this with their experience, intelligence, and moral courage to give them the flexibility to adapt to the circumstances they encountered." ${ }^{20}$ The above statement shows how the commander of the $23^{\text {rd }}$ Regiment used the mission orders to promote initiative. That also showed that his solders trusted him.

During the battle of Chipyong-ni, COL Freeman, had to coordinate many things, including the preparation of defense, reconnaissance, and counterattack. Nevertheless, based on the trust of his soldiers, he used mission orders and disciplined initiative to the best of his ability.

The Accept Prudent Risk Principle

The army definition of prudent risk is "a deliberate exposure to potential injury or loss when the commander judges the outcome in terms of mission accomplishment as worth the cost." ${ }^{21}$ That is essential for command; take risk to obey orders and achieve the task. The commander

18 Department of the Army, ADRP 6-0, Mission Command, Washington, DC: Government Printing Office, May 2012.

19 Department of the Army, ADRP 6-0, Mission Command, Washington, DC: Government Printing Office, May 2012.

20 K.E. Hamburger, Leadership in the Crucible, USA 2003, p. 65

21 Department of the Army, ADP 6-0, Mission Command, Washington, DC: Government Printing Office, 12 March 2014. focuses on creating opportunity by accepting reasonable risk.

This principle of mission command was used when Freeman made his decision to seize or defend the area. In order to provide coherent defense, he accepted that the enemy mortars could strike on each part of the unit. "It also was large enough to accommodate the regimental and battalion CPs, the reserve force, motor pools, and artillery positions. It was not, large enough to keep enemy mortars out of range or to prohibit effective enemy observation of the area." This decision would result in him being wounded by piece of mortar shrapnel. However, based on knowledge about enemy and operational environment he had to accept this risk and at the end this decision provide victory in battle.

\section{CONCLUSION}

The 23rd Infantry Regiment commander did well at using mission orders during each phase of the battle and accepted prudent risk throughout the operation. The 23 Regiment had developed a shared understanding of both their battle position, role within the regiment, and the Commander's overall intent during the mission execution. On that account, Freeman achieved a victory over a stronger enemy and stopped them in the Chipyong-ni area. Moreover, the literature analysis shows that using mission command philosophy has an impact not only on the conduct of the mission, but also on the morale of the entire unit "The compact between the leaders and the led generated high morale throughout the $23 \mathrm{~d}$ RCT despite the appalling cold, enemy action, and inevitable losses." 22

Based on the conducted research, it is confirmed that when done correctly, mission command empowers people and gives the commander tools to conduct the battle. We must not only understand this, but practice it throughout our organizations to succeed today and in the future.

\section{BIBLIOGRAPHY}

1. Barron, Leo. Korean War, Stackpole Books, USA 2015.

2. Hamburger, Kenneth E. Leadership in the Crucible, USA 2003.

3. Tucker, Spencer C., (ed.). Encyclopedia of the Korean War: A political, Social, and military History, vol. 1, California 2000.

4. Landry, Kenth Alan, Lt. COL. Leadership in Battle: The Siege at Chipyong-ni, Army article, September 2002.

5. Department of the Army, ADP 6-0. Mission Command, Washington, DC: Government Printing Office, 12 March 2014.

6. Department of the Army, ADRP 6-0. Mission Command, Washington, DC: Government Printing Office, May 2012.

22 K.E. Hamburger, Leadership in the Crucible, USA 2003, p. 120. 